\title{
DE MULHERES CAMPONESAS EM MOVIMENTO NA AMÉRICA LATINA AO MOVIMENTO DE MULHERES CAMPONESAS DO BRASIL
}

Isaura Isabel Conte*

\begin{abstract}
Resumo
A voz e as demandas políticas das mulheres camponesas no Brasil, na América Latina e, poderíamos dizer, em todos os continentes aparecem tardiamente na história. Isto não significa que se mantivessem passivas ou que não desencadeassem processos de luta, especialmente por mantimentos, água, terra, enfim, pela defesa de direitos à sobrevivência primeiramente, direitos do mundo do trabalho e, junto a estes, a reivindicação da cidadania. Neste ensaio, trataremos de movimentos realizados por mulheres camponesas da América Latina, destacando as indígenas, até chegar ao Movimento de Mulheres Camponesas (MMC) do Brasil, e podemos dizer, em síntese, que todas lutam pela saída da invisibilidade e por espaços políticos. As camponesas do MMC, desde 2004, ao formarem um movimento em âmbito nacional, assumem-se feministas.
\end{abstract}

Palavras-chave: Mulheres Camponesas. Lutas. América Latina. MMC.

\footnotetext{
* Doutoranda em Educação pela Universidade Federal do Rio Grande do Sul (Ufrgs) e bolsista do CNPq, com Doutorado "sanduíche" concluído na Universidade Nacional Autônoma do México (Unam), na Faculdade de Filosofia e Letras (FFyL). Militante do Movimento de Mulheres Camponesas (RS).E-mail: isauraconte@yahoo.com.br
} 


\section{Introdução}

Por meio deste ensaio, buscaremos realizar um brevíssimo recorrido histórico das mulheres camponeses em movimento no mundo, em especial na América Latina, para chegarmos ao atual Movimento de Mulheres Camponesas (MMC) do Brasil e sua afirmação da luta feminista. Partiremos da história possível de ser descrita aqui, abordando a crise de representação política/ de voz das mulheres, nos regimes republicanos, inclusive na democracia.

O exercício de historicizar as mulheres e suas organizações não tem sido fácil porque parte-se de retalhos fragmentados, que apresentam contradições profundas, sendo que em muitas situações "o modelo masculino parece bem mais atrativo em todos os aspectos”, diria Vidal (2004, p. 104). Nesse sentido, parafraseando Lagarde (2011), perguntaríamos: quem gosta de falar e de lembrar-se de seu(s) próprio(s) cativeiro(s)? E, muito pior, conseguir se dar conta da existência dele e suportá-lo.

Ao trazer presente os cativeiros das mulheres, sublinhamos que temos sido cativas, principalmente de acesso à esfera política/ poder, ou seja, grandemente impedidas de sermos sujeitos políticos. Diante desse aspecto, é importante destacar também, que a existência dos cativeiros está na própria sociedade patriarcal, não descolada do sistema capitalista e etnocida, embora se fale muito em interculturalismo nos últimos períodos.

O patriarcado pode ser descrito como sendo um sistema hierárquico, histórico e cultural em que as mulheres, de um lugar de destaque, passaram a ser consideradas inferiores, e assim foram obrigadas, em boa medida, a aceitarem e reproduzirem esta "ordem" como verdade. Lagarde (2011) nos ajuda na caracterização de modo mais detalhado, ao afirmar que o patriarcado é baseado no antagonismo genérico fundado enquanto concepção de mundo, norma, linguagem e instituições para o domínio dos homens e a opressão das mulheres; na clivagem do gênero feminino como produto da inimizade histórica entre as mulheres; no machismo cultural em que a inferiorização das mulheres é produto de sua opressão e a exaltação do masculino produto de sua virilidade. Ademais, essa autora destaca que o patriarcado não se limita à opressão feminina, mas a todos considerados inferiores na hierarquia, seja de sexo, exercício da sexualidade, raça/etnia, religiosidade, idade, etc. 
Contudo, destacamos que a constituição da sociedade patriarcal, de acordo com Muraro (2002), dá-se entre mais ou menos 10.000 e 20.000 anos e, anterior a esse período, as mulheres eram dominantes, ou seja, elas eram centrais, com importância reconhecida frente aos grupos, e, assim, acredita-se ter havido o período matriarcal.

Eisler (1996) prefere usar ao termo "matrilinear" ou "matrilinearidade" para se referir a esse período, enfatizando que ele fora o maior de todos até então na história da existência da humanidade. Destaca que eram as mulheres, no período matrilinear, as organizadoras da vida em sociedade e, portanto, em hierarquias quase inexistentes ou bastante flexíveis, faziam a organização do trabalho, das confraternizações e da distribuição dos alimentos entre todos. A autora se refere também à existência de uma sociedade de parceria, baseada na cooperação e não na competição, embora, não fosse algo sem conflitos, mas com um nível de violência quase inexistente.

De acordo com Gebara (2002), de forma geral, os estudos da história partem do patriarcalismo como se nós mulheres não tivéssemos outra história anterior, que desgraçadamente nos fez acreditar em nossa suposta incapacidade e docilidade: mulheres/ seres frágeis, culpadas pelos pecados dos homens e, portanto, inferiores a eles. Então, romper com a denominação e o lugar destinado às mulheres como seres de "segunda ordem" tem sido uma das saídas apontadas para justificar o patriarcalismo.

Ainda, segundo Gebara (2002), as organizações específicas de mulheres são bastante recentes e conseguem se fazer evidentes, com força coletiva, a partir do século XIX, pois o patriarcado fora tão forte que durante centenas de anos, senão alguns milênios, sufocava, reprimia e fazia desaparecer as vozes contestatórias. Contudo, apesar da grande proibição e perseguição, segundo Muraro (2002):

(...) durante o período da Renascença, continuaram as mulheres pobres, a serem as grandes questionadoras. Elas tomavam parte em todas as revoltas camponesas e exerceram papel preponderante não só na reforma protestante como na guerra civil inglesa e em muitos levantes camponeses na Europa até o século XVIII (MURARO, 2002, p. 128).

Entretanto, sobre o que é relatado na história oficializada, pouco protagonismo ou quase nada se pode perceber com relação a elas, sendo um exemplo do que acontecia com aquelas que 
destoavam de seu sexo Joana d'Arc. Conforme destaca Perrot (2005), diante de todos os processos de luta populares, lá estão as mulheres, mas de protagonistas são relegadas a secundárias. Quando as pautas específicas das mulheres aparecem no "geral da luta operária", por exemplo, passam a ser tidas como de menos importância, quando não, as protagonistas, consideradas divisoras da luta por seus companheiros. No século XIX, quando se organizam e suas contestações são evidenciadas, assim são descritas

Aquelas 'pobres cabeças loucas', 'vítimas', 'perdidas', aparecem como incapazes de agir por sua própria iniciativa. Atrás delas, procura-se o condutor masculino. Aquelas 'inofensivas', é preciso tratá-las como crianças (...) em suma, elas não são levadas a sério (PERROT, 2005, p. 160-161).

Ao realizar estes apontamentos, queremos sublinhar que há outra parte, ou seja, a maior parte da história que ou não é contada ou é distorcida. Eisler (1996), em sua descrição a partir de estudos arqueológicos exaustivos em diversas partes do mundo, afirma que do sagrado que estava com as mulheres passa-se à consideração do profano e do pecado. Nesse sentido, Muraro (2002) complementa enfatizando que os homens, no patriarcado, tomaram para si o reino da cultura e estabeleceram as normas morais, ao passo que relegaram às mulheres ao reino da natureza/matéria/mater. Logo: a divisão do público e do privado, do importante e do secundário.

\section{Mulheres camponesas da América Latina e suas organizações}

Iniciamos esta sessão destacando que as mulheres camponesas da América Latina têm em comum uma história muito semelhante de colonização e, a partir deste fator, elas foram as vencidas, estupradas, procriadoras à força, caçadas no mato, amansadas para posterior casamento, obrigadas ao cristianismo católico. Eram elas também as conhecedoras da agricultura e da natureza, multiplicadoras das sementes e das espécies várias, domesticadoras de pequenos animais, inventoras dos pratos da culinária, de instrumentos de trabalho, "bruxas" conhecedoras da medicina, enfim, trabalhadoras e mantenedoras da vida dos grupos. 
Essas histórias com mais ou menos detalhes são descritas

nas obras Casa Grande E Senzala, salvo o preconceito com os indígenas de forma generalizada; na obra de Darcy Riberiro $O$ Povo Brasileiro, com ressalvas sobre o que é dito das mulheres índias, e negras na escravidão; e, de forma bem mais crítica, nos vários artigos organizados por Mary Del Priore em Mulheres na história do Brasil. Contudo, com preconceito, olhar machista ou não, a partir destas fontes não há como negar que ao tratar de mulheres camponesas na América Latina estamos nos referindo especialmente às mulheres indígenas e negras escravas, e mais uma pequena parcela de mulheres descendentes de europeus, atualmente empobrecidas e trabalhadoras no campo, compreendendo a pequena agricultura ou o campesinato.

$\mathrm{O}$ protagonismo destas mulheres durante muito tempo esteve invisibilizado, pois o colonialismo se firmou sobre a imagem das índias como "as selvagens e sujas, mas tentadoras" e "das negras (escravizadas) libidinosas e traiçoeiras" para justificar a invasão e continuá-la. Mais tarde, a mulher outra vez é utilizada para simbolizar e afirmar as repúblicas/nações e os nacionalismos. O primeiro fato é demonstrado por meio de estudos de Ramineli (2004), em que o autor argumenta que a imagem da índia velha de seios caídos foi levada da América para o Velho Mundo, para convencimento de que haviam selvagens/ bárbaros/não cristãos avessos à civilização, o que justificaria a colonização e o extermínio das populações. Além disso, pinturas da época colonial representavam as mulheres em rituais canibais, sendo que as velhas eram acusadas de praticar orgias sexuais. Tudo deveria parecer decadente e monstruoso, segundo o autor, sendo que as índias velhas enrugadas e de seios caídos foram desta forma fortemente estereotipadas, pois se apresentavam como obstáculos aos interesses coloniais, na medida em que eram as detentoras do conhecimento.

O segundo fato é ilustrado por Vidal (2004) e Yuvas-Davis (2004), ambas estudiosas da causa indígena americana.

Mujeres y nación han sido asociadas cercanamente: el nacionalismo tiende a identificar a la nación con los cuerpos de las mujeres: son las que debe usar el 'vestido tradicional, son vistas como las productoras de bebés para la pátria y resguardo del hogar para los hombres en el frente, penalizadas si se acuestan con extranjeros, violadas por los enemigos de la nación'(VIDAL, 2004, p. 90). 
No mesmo sentido que Vidal, Yuvas-Davis (2004) aponta para a descrição das mulheres como símbolo da coletividade de um projeto nacional, obviamente não pensado por e com elas. Segundo a autora, as mulheres, na tentativa de representação da nação, deveriam (e devem) representar a honra nacional e coletiva e, de outro modo, castigadas exemplarmente quando se enamoravam ou confraternizavam com o considerado inimigo (da nação). Nesta fase, a imagem da mulher já é da mestiça, bastante europeizada.

Gutiérrez (2004, p. 26) sintetiza a ideia do nacionalismo sobre o corpo das mulheres da seguinte forma: "que las mujeres sean identificadas como 'guardianas de los valores tradicionales' mientras que los hombres han sido los constructores y promotores del Estado".

No Brasil, no período imperial (1822-1889), instalou-se um projeto colonizador baseado na ideologia do branqueamento do país, devido ao grande contingente de população negra escravizada. Para tal empreendimento, optou-se pela imigração europeia que pretendia povoar/branquear as regiões Sul e Sudeste, principalmente, através do trabalho dos imigrantes europeus, na medida em que a importação de escravos estava cada vez mais cerceada e, por isso, muito onerosa a partir de meados do século XIX (ZARTH, 2002).

Assim, as mulheres imigrantes deveriam procriar muitos filhos para a garantia de mão de obra nas lavouras e, como eram brancas, foram consideradas mais puras, com status superior às mestiças, índias ou negras que estavam no país. Pedro (2004) enfatiza o fato de que as mulheres (brancas) deveriam manter a imagem de santas, recatadas e trabalhadoras ou trabalhadeiras. Eram descritas como mais bonitas, educadas, de sexualidade controladíssima e também mais obedientes e submissas aos maridos; entretanto, a literatura pouco enfatiza que eram as pobres ou paupérrimas sobrantes e sem terras da Europa.

A mesma historiadora aponta que com a forte influência do positivismo no Sul do Brasil, essas mulheres aparecem como complementares dos maridos (pensantes). De outro modo, as negras e indígenas, por causa de suas etnias, foram rechaçadas e consideradas inferiores, fato este também comum em toda a América colonizada. De acordo com Vidal (2004, p. 103) "la naturalización de la desigualdad social a través de las diferencias 
de sexo y 'raza' se ha constituido en un echo central al perpetuar las desigualdades genéricas y de clase”.

Estas desigualdades continuam colocando as mulheres como as mais empobrecidas do planeta (MÉSZAROS, 2002), pois segundo o estudioso, elas compõem os $70 \%$ de miseráveis do mundo. $\mathrm{Na}$ afirmação de Gutiérrez (2004), os estados-nações que se constituíram foram idealizados e oficializados sem a participação das mulheres e das indígenas, em particular, ou seja, uma exclusão de gênero que atravessa fronteiras etnorraciais. Como poderiam elas reivindicar algo se não eram consideradas parte da nação? Seus corpos, então mestiços, simbolizavam as nações que surgiam como tal e deveriam produzir mais e mais mão de obra e homens para as guerras. Assim, uma nação poderia ampliar e demarcar fronteira, sobrepor-se às demais e, enquanto isso, as mulheres trabalhavam e sustentavam o país todo e as guerras; no entanto, permaneciam invisibilizadas, seus cérebros não contavam, eram consideradas desviantes e não dignas de confiança, pois, indiferentemente de nacionalidade, eram descendentes de Eva, como afirma Gebara (2002).

Embora as mulheres pouco significassem frente aos projetos nacionais desenvolvidos, elas eram parte e sofriam, acima de tudo, as consequências. Mulher ainda não constituía uma pauta, tampouco gênero era algo recorrente nos idos do século XVIII na América Latina, pelo que vimos estudando. Porém, estavam inseridas nas grandes contradições geradas com o acúmulo de riqueza de um lado e pobreza de outro; faziam parte do contingente de gentes pobres, morriam aos montes nos partos quando a demanda era aumentar o número de braços para o trabalho; estavam com as crianças e suas trouxas na disputa por terra, trabalho e recursos naturais para sobreviver.

Toda essa crise bastante aparente, embora negada e silenciada pelos governantes, já vinha sendo arrastada desde a invasão do Brasil, por mais que a cada conhecida revolta, o exército de Portugal ou Espanha ou, até ambos aliados, e depois as forças imperiais eram chamadas para combater os rebelados, que em poucos casos logravam algo mais que morte ou com mais sorte, fugas. Para deixar ainda mais evidente, Canclíni (1998) descreve o contexto latino-americano em que eclodem movimentos populares, destacando como fator:

(...) as oligarquias liberais do final do século XIX e início do século $\mathrm{XX}$ teriam feito de conta que constituíam Estados, mas apenas organizaram algumas áreas da sociedade para promover um desenvolvimento subordinado e inconsciente; fizeram de conta que formavam 
culturas nacionais e mal constituíram cultura de elite, deixando de fora enormes populações indígenas e camponesas que evidenciam sua exclusão em mil revoltas (CANCLÍNI, 1998, p. 25).

Diante deste contexto, embora os homens apareçam por muito tempo como únicos lutadores e protagonistas, as mulheres sempre estiveram à frente de processos de luta, especialmente, por direito a água, lenha, alimentos e teto desde os primórdios da humanidade. Eram elas que desencadeavam e faziam motins por víveres e, diante disso, não poucas vezes, tratadas como loucas ou inconsequentes e infantis (PERROT, 2010).

Ainda que escritas oficiais tenham negado e "não percebido" o protagonismo feminino e suas necessidades específicas, por outro lado, surgem cada vez mais estudiosas mulheres que se dedicam a desvelar e evidenciar histórias, desde Joana Inés de la Cruz, no México, ainda no século XVII, e Mary Wollstonecraft, no século XVIII, na Inglaterra, como primeiras vozes de denúncia da situação das mulheres. Depois delas, no século XIX, já são evidentes uma porção de rebeldes contra a ordem patriarcal machista, como Maria Lacerda de Moura, no Brasil; Josefina Pelliza de Sagaza, na Argentina; Soledad Acosta Samper, na Colômbia; Luiza Pérez de Zambrana e Gertrudiz Gómez de Avellaneda, em Cuba; Mercedes Cabello de Carbonera; e Rosa de Amézaga e Teresa González de Fanning, no Peru (FORNETBETANCOURT, 2009).

No século XX, o feminismo já é bastante evidenciado, especialmente na Europa e nos Estados Unidos, devido a movimentos realizados pelas mulheres no século XIX, período em que justamente se dava a formação da maioria dos estadosnação na América, segundo Gutiérrez (2004). De acordo com Lagarde (2011, p. 54), "el feminismo contiene la más importante innovación social y cultural en el mundo contemporâneo y ha contribuido a transformar de manera creativa la vida de las mujeres”. Segundo Gebara (2002), o feminismo é um movimento político pela libertação da humanidade.

No século $X X$, muitas mulheres mais se somaram e protagonizaram a luta pela causa feminina e/ou feminista, tendo notoriedade a influência das socialistas feministas como Clara Zatkin e Alexandra Kolontai, da ex-URSS. Alguns homens também, mundo afora, puseram-se a escrever e publicar em favor das mulheres, com ênfase ao acesso a (outra) educação, como Emilio Frugoni, no Uruguai; Engles e August Bebel, na 
Alemanha, e Luis Emilio Recabarren, no Chile (FORNETBETANCOURT, 2009).

Contudo, as mulheres camponesas pouco acesso tinham às teorias e aos debates feministas, embora, de alguma forma, alguns avanços e conquistas as tocavam, mesmo que indiretamente. Para elas, o acesso à educação mínima foi tardio, de forma generalizada no contexto latino-americano. De acordo com Paludo (2001) e Gutiérrez (2004), uma educação de primeiras letras massiva no campo se deu entre 1920 e 1940, sendo que anteriormente a esse período, a educação às populações do campo e das florestas, segundo Saffioti (1969), chegava através da igreja/catequização, isso quando chegava.

Logicamente, o acesso mínimo à educação possibilitava alguma mudança na vida das mulheres: saber minimamente ler e escrever, embora fazendo o recorte étnico ao falar do campo, indígenas e negros, inclusive mulheres, eram os que mais ficavam de fora, pelo próprio curso do desenvolvimento eleito pelos governantes. As mulheres, como que por um "destino" traçado pelo patriarcado, eram deixadas de lado naturalmente, pois deveriam casar e ter inúmeros filhos, um ideal generalizado na América Latina ao menos até a metade do século XX e, para isso, não era preciso saber muito, aliás, nem era bom saber demais para uma mulher, como pontua Saffioti (1969).

Afora esse fator, elas, na América Latina, eram e continuam sendo fortemente excluídas do acesso a terra. Primeiramente, ou saíram da escravidão ou servidão ou em fuga de ambos sem nada. A luta constante por reconhecimento de posse de reservas indígenas, quilombos ou no parco pedaço conseguido de outra maneira, para as imigrantes, um pouco mais fácil, continua latente. Quando há posse registrada, estudos de Deere e León (2002) apontam que os homens herdam cinco vezes mais que as mulheres e, decorrente disso, são elas que ficam em situação vulnerável com os filhos as e filhas. As autoras também destacam a falta de estatísticas para estes dados com relação ao gênero, demarcando que as pesquisas dos censos são muito frágeis ou sexistas.

Terra e território são fatores fundamentais que fazem parte da identidade do povo campesino, pois é por meio deles que se possibilita a própria (re)produção da vida/cultura. Por causa de ambos, não foram poucos os conflitos, revoltas e guerras de povos indígenas, negros e mestiços que ficaram à margem dos processos de "desenvolvimento" dos países. 
$\mathrm{Na}$ América Latina, de forma geral, constata-se o (res) surgimento de várias organizações camponesas após caírem os regimes militares totalitários. O povo vinha a reclamar terra e cidadania e, neste bojo, surgem também organizações específicas de mulheres camponesas e/ou indígenas, de forma especial no Brasil, na Bolívia, no Paraguai e no Chile (CONTE, MARTINS e DARON, 2009). De acordo com Espeland (2004), no México, organizações indígenas se levantam com força a partir da década de 1970 e, nelas, as mulheres seguiam suas organizações mistas, sem que isso significasse espaço particular para as suas demandas.

De acordo com a mesma autora, no México e nos demais país latinos de língua espanhola, as organizações específicas de mulheres indígenas ou de dentro de suas organizações mistas aparecem no início da década de 1990, fortemente impulsionadas pelas mulheres do Exército Zapatista de Libertação Nacional (EZLN), as quais publicizaram em 1993 a Ley Revolucionária de las Mujeres Zapatistas com 10 pontos de exigência. Em 1995, no Equador as mulheres indígenas também fizeram seu primeiro encontro nacional, ou seja, a década de 1990 fora com vários outros encontros de mulheres indígenas nos países, intrapaíses, em grupos de trabalhos, etc., e assim se seguiu no novo século (ESPELAND, 2004).

É nesse mesmo contexto de possibilidades e de negação que começam a surgir, no Brasil, várias organizações de mulheres camponesas, que vão tomando forma também a partir do final da década de 1970. Algumas surgem de dentro de pastorais sociais, como a Comissão Pastoral da Terra (CPT) ainda sob o impulso da teologia da libertação, outra parte de sindicatos de trabalhadores rurais filiados à Central Única dos Trabalhadores (CUT), ora com alguma contribuição de sistemas de assistência técnica como o Emater ou similares.

De acordo com Conte, Martins e Daron (2009), no Rio Grande do Sul é originada a Organização de Mulheres da Roça (OMR) em 1983, concomitantemente e em profundo companheirismo com mulheres camponesas do Estado de Santa Catarina, que consolidavam o Movimento de Mulheres Agricultoras (MMA). Desde o surgimento dessas organizações específicas de mulheres da roça, as bandeiras de luta explícitas eram por acesso a direitos, cidadania e libertação das mulheres de todos os tipos de opressão e exploração.

Ainda, segundo os mesmos autores, em suas origens essas organizações, assim como outras que iam surgindo em outros 
estados da federação, às vezes se mesclavam e contavam com a participação e contribuição de mulheres de organizações populares camponesas mistas, que também percebiam a ausência de direitos (principalmente previdenciários), acesso à saúde e educação para as mulheres do campo. Além delas, outras mulheres e parte de outras organizações populares da cidade e setores sindicais estiveram no apoio e impulsionando a luta, e, obviamente, também fazendo evidenciar contradições. As mulheres da roça queriam ser ouvidas em suas demandas e pautas específicas. Algo que em grande medida não era possibilitado nos espaços em que atuavam, especialmente em sindicatos.

A busca por reconhecimento da categoria de trabalhadora rural/agricultora foi um dos motes iniciais junto à discussão no processo da elaboração da Constituinte, culminando na Constituição Federal de 1988, em que a categoria trabalhador/a rural foi reconhecida no Brasil. Elas se perceberam negadas de direitos básicos, inclusive acesso a documentos pessoal e profissional e, por isso, "não existiam" frente ao Estado. Assim, assumiram a luta específica de gênero no campo após a trajetória delineada pelo MMA que consolidou em 2004 o Movimento de Mulheres Camponesas do Brasil no I Congresso Nacional do MMC, que aconteceu em Brasília de 05 a 08 de março, onde estiveram presentes cerca de 1.800 militantes de 14 estados da federação, que haviam assumido a organização autônoma das mulheres camponesas. Foi nesse momento em que, após profunda análise das lutas travadas, este Movimento se declara feminista, sem negar a identidade camponesa e popular.

A caminhada do MMC Brasil enquanto Movimento continuou sendo consolidada com o acréscimo ou a explicitação do feminismo, que anteriormente se definia como um movimento popular de gênero e classe. Em fevereiro de 2013, de 18 a 21, faz seu $1^{\circ}$ Encontro Nacional, optando por não seguir a linha de congresso devido ao caráter de encontro e debates para entendimento comum de pautas e lutas a serem fortalecidas pela libertação das mulheres, pautando fortemente nos últimos anos a luta de combate à violência cometida contra todas as mulheres; por outro projeto de agricultura, feminista e camponês, contra o agronegócio e seus pacotes e pela defesa e implementação da agroecologia com produção de alimentos saudáveis; por acesso a direitos, reconhecimento e espaços de poder às mulheres. Nesta direção, afirmam-se como palavras de ordem: "Sem feminismo 
não há socialismo"; "Na sociedade que a gente quer, basta de violência contra a mulher"! "fortalecer a luta, em defesa da vida, todos os dias!" e muitos outros.

Souza-Lobo (2011) descreve com muita propriedade que a partir dos anos de 1980 no Brasil, o feminismo sofreu um refluxo, após o impulso da própria ONU em 1975 com a declaração da Década da Mulher, devido à institucionalização, em grande medida. Assim, ela afirma que se passa a ter no país um feminismo envergonhado. Não discordamos da autora, pois segundo ela, houve um refluxo no movimento feminista brasileiro, mas enfatizamos que, desde a academia, não se conseguia e talvez pouco se consegue enxergar um feminismo diferente do que ocorria no campo.

$\mathrm{Na}$ década de 1980, as mulheres do campo no Brasil saíram às milhares às ruas, reivindicando direitos e libertação. Logo, as mais ousadas denunciavam a falta de espaços de decisão e então afirmam a luta específica em movimentos autônomos, os quais vieram a consolidar o MMC no ano de 2004, embora a palavra "feminismo" ainda não estivesse explicitada.

Atualmente no Brasil, podemos afirmar que há um feminismo camponês com cara e jeito próprios, consolidando sua própria definição/identidade a partir da vida das mulheres do campo, suas necessidades e suas não aceitações/rebeldias. Tais mulheres pautam autonomia de si mesmas e de suas organizações desde os idos anos 1980 e acreditam nas novas relações de gênero e também outras formas de relação com a natureza, construções estas que não se dão sem conflitos, senão não há mudança. Rompem com os espaços naturalizados para as mulheres e, ao mesmo tempo, reforçam o lugar de mulher da roça, mostrando e apontando que existem muitos outros lugares a serem ocupados pelas mulheres, além da roça, mas que acima de tudo a roça precisa ser um lugar bom de viver.

\section{Considerações finais}

Entendemos a partir da participação militante no MMC que o feminismo camponês é ancorado na autonomia das mulheres e de suas organizações, que caracterizam a trajetória de tal Movimento. Essa autonomia é válida também no que refere ao espaço de produção, na medida em que elas já não aceitam os piores pedaços de terra para cultivar as chamadas "miudezas" 
e reivindicam a melhor terra para a produção das grandezas, entendidas como alimentos saudáveis.

Acreditam e constroem um feminismo camponês também solidário, especialmente com relação a outras mulheres empobrecidas e violentadas, seja devido ao sistema capitalista e patriarcal, seja por violência física, por parte dos cônjuges. É bastante comum a organização de grupos desde as comunidades e a vizinhança, surgindo assim grupos produtivos com fins de gerar renda. Elas, então, aprendem umas com as outras e fazem a gestão e, desse modo, vão rompendo com tabus, preconceitos e medos, ao mesmo tempo em que mostram para as demais que é possível. Parece ser pouco, parece ser um feminismo tímido, mas, parafraseando Gebara (2002), significam grandes passos se comparados aos mais de 2 mil anos que ficaram reservadas ao espaço privado.

O feminismo camponês assumido pelo MMC do Brasil é construído em pareceria com as lutas de mulheres de organizações mistas, de forma especial, junto à Via Campesina. Avança-se coletivamente e se dá força entre organizações de mulheres em pautas e lutas conjuntas. Por isso, para o MMC, o feminismo camponês não é individualizado, ele precisa ser cada vez mais coletivizado para ter mais força frente à sociedade capitalista-patriarcal, individualista, racista, homofóbica, e sabe-se que há muito a construir.

Voltando ao diálogo com as demais lutas de mulheres no campo, segundo Espeland (2004), as mulheres indígenas do México também pautam por autonomia de seus movimentos e de seus corpos. Quando se referem ao feminismo, negam aquele que conhecem como sendo de classe média e importado, mas apostam em suas pautas comuns de mulheres para seguirem avançando, afirmando, portanto, uma outra forma de feminismo.

Para concluir, enfatizamos o depoimento de uma mulher indígena do México, que, ao tratar da luta pelo direito à autonomia dos grupos étnicos frente à nação, reforça a autonomia econômica e política e o acesso aos meios de produção: "la democrácia tiene que ser construida en casa primero"(VIDAL, 2004,p. 106), e, nesse sentido, todas as camponesas parecem concordar. Elas associam o poder político necessário nas esferas públicas e comunidades com o poder de decisão e autonomia que vão construindo (forçadamente) dentro de casa. Elas querem transformações no todo e não pela metade, do micro ao macro e vice-versa. Por isso, concluímos com um alerta a partir de suas lutas: cuidado com estas mulheres que sempre souberam selecionar as melhores sementes! 


\section{Referências}

CANCLÍNI, Néstor García. Culturas híbridas: estratégias para entrar e sair na modernidade. Tradução de Heloíza Pezza Cintrão e Ana Regina Lessa. 2a ed. São Paulo: USP, 1998.

CONTE, Isaura Isabel; MARTINS, Mariane Denise; DARON, Vanderléia Pulga. Movimento de Mulheres Camponesas: na luta para a constituição de uma identidade feminista, popular e camponesa. In: PALUDO, Conceição (Org.). Mulheres, luta e resistência: em defesa da vida. São Leopoldo: Cebi, 2009. p. 86-132.

DEERE, Carmen Diana; LEÓN, Magdalena. O empoderamento da mulher: direitos a terra e direitos à propriedade na América Latina. Tradução de Letícia Vasconcelos Abreu, Paula Azambuja Rossato Antinolfi e Sônia Terezinha Gehering. Porto Alegre: Ufrgs, 2002.

EISLER, Raiane. O prazer sagrado: sexo, mito e política do corpo. Tradução de Ana Luiza Dantas Borges. Rio de Janeiro: Rocco, 1996.

FORNET-BETANCOURT, Raúl. Mujer y filosofía en el pensamiento iberoamericano. Momentos de una relación difícil. Barcelona: Antrophos editorial, 2009.

FREYRE, Gilberto. Casa grande \& senzala. $46^{a}$ ed. Rio de Janeiro e São Paulo: Record, 2002.

GEBARA, Ivone. Cultura e relações de gênero. São Paulo: Cepis, 2002.

GUTIÉRREZ, Natividad Chong. Tendencias de estudio de nacionalismos y mujeres. In: GUTIÉRREZ, Natividad Chong (Coord.). Mujeres y nacionalismos en América Latina. De la independencia a la nación del nuevo milenio. Universidad Nacional Autónoma de México. Instituto de Investigaciones Sociales, 2004. p. 19-66.

LAGARDE, Marcela y de los Ríos. Los cautiverios de las mujeres. Madresposas, monjas, presas, putas y locas. Madrid: Horas y Horas la editorial, 2011.

MÉSZÁROS, István. Para além do capital. Rumo a uma teoria da transição. Tradução de Paulo César Castanheira; Sérgio Lessa. São Paulo: Unicamp e Boitempo, 2002.

MURARO, Rose Marie. A mulher no terceiro milênio. $8^{\mathrm{a}}$ ed. Rio de Janeiro: Rosa dos Tempos, 2002.

PEDRO, Joana Maria. Mulheres do Sul. In: PRIORE, Mary Del (Org.). In: Histórias das mulheres no Brasil. São Paulo: Contexto/ Unesp, 2004. p. 278-320. 
PERROT, Michelle. As mulheres ou os silêncios da história. Tradução de Viviane Ribeiro. Bauru/São Paulo: UDUSC, 2005.

Os excluídos: operários, mulheres e prisioneiros. Tradução de Deise Bottmann. 6ª reimp. São Paulo: Paz e Terra, 2010.

PRIORI, Mary Del (Org). Histórias das mulheres no Brasil. São Paulo: Contexto/Unesp, 2004.

RAMINELI, Ronald. Eva Tupinambá. In: PRIORE, Mary Del (Org.). In: Histórias das mulheres no Brasil. São Paulo: Contexto/Unesp, 2004. p. 11-41.

RIBEIRO, Darcy. O Povo Brasileiro. A formação e o sentido do Brasil. 2a ed. São Paulo: Companhia das Letras, 1995.

SAFFIOTI, Helleieth. A mulher na sociedade de classes. Mito e realidade. Rio de Janeiro: Vozes, 1969.

VIDAL, Margarita Zárate. Multiculturalismo, poder y mujeres. In: GUTIÉRREZ, Natividad Chong (Coord.). Mujeres y nacionalismos en América Latina. De la independencia a la nación del nuevo milenio. Universidad Nacional Autónoma de México. Instituto de Investigaciones Sociales, 2004. p. 83-116.

YUVAL-DAVIS, Nira. Género y nación. In: GUTIÉRREZ, Natividad Chong (Coord.). Mujeres y nacionalismos en América Latina. De la independencia a la nación del nuevo milenio. Universidad Nacional Autónoma de México. Instituto de Investigaciones Sociales, 2004. p. 67-82.

ZARTH, Paulo Afonso. Do arcaico ao moderno. O Rio Grande do Sul agrário do século XIX. Ijuí: Unijuí, 2002.

\title{
WOMEN PEASANT MOVING IN LATIN AMERICA TO THE MOVEMENT OF BRAZIL WOMEN PEASANT
}

\begin{abstract}
The voice and the political demands of peasant women in Brazil, Latin America, and, one might say, on every continent appears late in the story. This does not mean that they would remain passive or not unleashed processes of struggle, especially for provisions, water, land, finally, for the defense of rights to survival first, rights in the workplace, and in or adjacent to the claim of citizenship. In this essay we will try to moves made by peasant women in Latin America, highlighting the indigenous, until you reach the Movement of Peasant Women in Brazil, and we can say in summary that all fighting for the output of invisibility and political spaces. The peasant of MMC, since 2004, to form a nationwide movement, feminists are assumed.
\end{abstract}

Keywords: Peasant Women. Struggles. Latin America. MMC. 